\title{
Effect and safety of bevacizumab-containing chemotherapy treatment in Chinese patients with metastatic colorectal cancer
}

This article was published in the following Dove Press journal:

OncoTargets and Therapy

29 April 2013

Number of times this article has been viewed

\section{Qian Wu \\ Yan Shi \\ Li Chen \\ Xiaoyi Xiao \\ Guanghai Dai}

Department of Multimodality Therapy Oncology, Chinese PLA General Hospital, Beijing, People's Republic of China
Correspondence: Dai Guanghai Department of Multimodality Therapy Oncology Unit I, Chinese PLA General Hospital, 28 Fuxing Road, Beijing, People's Republic of China Tel +86 I38 0 I23238I

Email daigh60@sohu.com
Purpose: To review the clinical data and treatment efficacy of bevacizumab in Chinese patients with metastatic colorectal cancer (mCRC).

Patients and methods: A total of 96 patients with mCRC treated by chemotherapy plus bevacizumab in the PLA General Hospital between December 2005 and August 2012 were analyzed retrospectively by overall response rate, disease-control rate, progression-free survival (PFS), and overall survival (OS). The tumor responses were assessed by the Response Evaluation Criteria in Solid Tumors guidelines.

Results: A total of 96 patients with mCRC were identified. Median age was 53.6 years. Eastern Cooperative Oncology Group performance status was 0-2. By the end of follow-up (August 20, 2012), 54 patients exhibited progression (56.3\%), and 39 (40.6\%) patients had died. A total of $27(28.1 \%)$ achieved partial response, and 48 patients (50.0\%) had stable disease, exhibiting an overall response rate of $28.1 \%$ and a disease-control rate of $78.1 \%$. The response rates of the firstline, second-line, and third-line (or later) therapy were $41.7 \%, 21.9 \%$, and $15.8 \%$, respectively. The median durations of the PFS and OS were 8.13 months and 14.80 months, respectively. The median durations of the PFS were 12.70 months, 8.30 months, and 6.40 months for first-line, second-line, and third-line (or later) therapy, respectively, and the median durations of the OS were 24.03 months, 14.90 months, and 11.03 months for first-line, second-line, and third-line (or later) therapy, respectively.

Conclusion: A bevacizumab-containing chemotherapy regimen was well tolerated and effective in Chinese patients with mCRC.

Keywords: colorectal cancer, metastasis, Chinese, bevacizumab, efficacy

\section{Introduction}

Colorectal cancer is the fifth most common malignancy and the leading cause of cancer death in the People's Republic of China. Recently, the incidence of colorectal cancer has been increasing steadily, and over 100,000 deaths occur annually in the People's Republic of China. ${ }^{1}$ Currently, the standard treatment of patients with metastatic colorectal cancer ( $\mathrm{mCRC}$ ) depends on chemotherapies with fluoropyrimidines, irinotecan, and oxaliplatin. In addition, antibodies against vascular endothelial growth factor (bevacizumab), epidermal growth-factor receptor (cetuximab and panitumumab) have been shown to prolong progression-free survival (PFS) in patients with mCRC. ${ }^{2-4}$

Bevacizumab is a humanized monoclonal antibody that can neutralize different types of vascular endothelial growth factor. ${ }^{5,6}$ Many studies have shown that treatment with bevacizumab and cytotoxic chemotherapy benefits patients with $\mathrm{mCRC},{ }^{7-10}$ 
and bevacizumab has been recommended as the first and second line of reagent for patients with mCRC. ${ }^{11}$

While the benefits of treatment with bevacizumab are well documented in Caucasian patients with mCRC, the effect and safety of treatment with bevacizumab in Chinese patients with mCRC has not been clarified. This retrospective study aimed at investigating the effect and safety of treatment with bevacizumab in Chinese patients with $\mathrm{mCRC}$.

\section{Materials and methods}

\section{Patients}

This retrospective study included 96 patients with mCRC who had been treated with chemotherapy plus bevacizumab between December 2005 and August 20, 2012 in the PLA General Hospital. The inclusion criteria were: histologically confirmed $\mathrm{mCRC}$; age $\geq 20$ years, and a life expectancy $>3$ months; Eastern Cooperative Oncology Group (ECOG) performance status of 0-2; adequate hematologic (an absolute neutrophil count $>1500 / \mu \mathrm{L}$, hemoglobin $>9.0 \mathrm{~g} / \mathrm{dL}$, and a platelet count $>75,000 / \mu \mathrm{L}$ ), hepatic (bilirubin $<2.0 \mathrm{mg} / \mathrm{dL}$ and transaminase levels $<3$ times the upper normal limit), and renal functions (creatinine $<1.5 \mathrm{mg} / \mathrm{dL}$ and urinary excretion $\leq 500 \mathrm{mg}$ of protein per day). The exclusion criteria were the presence of clinically significant cardiovascular disease; uncontrolled hypertension; central nervous system metastasis; major surgery within 6 weeks; pregnancy or lactation; nonhealing wounds; preexisting bleeding diatheses or coagulopathies; the need for full-dose anticoagulation.

Written informed consent was obtained from individual patients and the experimental protocol was approved by the ethical committee of the PLA General Hospital.

\section{Treatment}

Among the 96 patients included, 48 patients received bevacizumab combined with oxaliplatin-containing chemotherapy, 39 patients received bevacizumab combined with irinotecancontaining chemotherapy, and nine patients received bevacizumab combined with fluorouracil plus Leucovorin (LV). Oxaliplatin-containing chemotherapy included oxaliplatin + capecitabine (XELOX) and fluoropyrimidine + oxaliplatin (FOLFOX). Irinotecan-containing chemotherapy consisted of fluoropyrimidine + irinotecan and irinotecan alone. All of the patients were treated intravenously with $5 \mathrm{mg} / \mathrm{kg}$ bevacizumab (Avastin; Genentech, San Francisco, CA, USA) over 30 -minutes every 2 weeks or $7.5 \mathrm{mg} / \mathrm{kg}$ every 3 weeks, prior to the chemotherapy (Table 1).
Table I Details of chemotherapy regimens

\begin{tabular}{|c|c|c|}
\hline Chemotherapy & $\mathbf{n}$ & Regimens \\
\hline FOLFOX & 28 & $\begin{array}{l}\text { Oxaliplatin } 85 \mathrm{mg} / \mathrm{m}^{2} \text { IV over } 2 \text { hours, day I; } \\
\text { Leucovorin } 200 \mathrm{mg} / \mathrm{m}^{2} \text { IV day I-2; 5-FU } \\
200 \mathrm{mg} / \mathrm{m}^{2} \mathrm{IV} \text { bolus on day I-2, } \\
600 \mathrm{mg} / \mathrm{m}^{2} / \text { day, } 2 \text { days' continuous infusion. } \\
\text { Repeat every } 2 \text { weeks. }\end{array}$ \\
\hline XELOX & 20 & $\begin{array}{l}\text { Oxaliplatin } 130 \mathrm{mg} / \mathrm{m}^{2} \text { IV day I; capecitabine } \\
850-1000 \mathrm{mg} / \mathrm{m}^{2} \text { twice daily for I } 4 \text { days. } \\
\text { Repeat every } 3 \text { weeks. }\end{array}$ \\
\hline FOLFIRI & 31 & $\begin{array}{l}\text { Irinotecan } 180 \mathrm{mg} / \mathrm{m}^{2} \mathrm{IV} \text { over } 30- \\
90 \text { minutes, day I; leucovorin } 200 \mathrm{mg} / \mathrm{m}^{2} \mathrm{IV} \\
\text { day I-2; } 5-\mathrm{FU} 200 \mathrm{mg} / \mathrm{m}^{2} \mathrm{IV} \text { bolus on } \\
\text { day I-2, } 600 \mathrm{mg} / \mathrm{m}^{2} / \text { day, } 2 \text { days' continuous } \\
\text { infusion. Repeat every } 2 \text { weeks. }\end{array}$ \\
\hline Irinotecan & 8 & $\begin{array}{l}\text { Irinotecan I25 mg/m² IV over } 30- \\
90 \text { minutes, day I, } 8 \text {. Repeat every } 3 \text { weeks. }\end{array}$ \\
\hline 5-FU/leucovorin & 9 & $\begin{array}{l}\text { Leucovorin } 500 \mathrm{mg} / \mathrm{m}^{2} \text { IV over } 2 \text { hours on } \\
\text { day I, followed by } 5 \text {-FU bolus } 400 \mathrm{mg} / \mathrm{m}^{2} \\
\text { and then } 1200 \mathrm{mg} / \mathrm{m}^{2} / \text { day, } 2 \text { days' continuous } \\
\text { infusion. Repeat every } 2 \text { weeks. }\end{array}$ \\
\hline
\end{tabular}

Abbreviations: FOLFOX, fluoropyrimidine + oxaliplatin; XELOX, oxaliplatin + capecitabine; FOLFIRI, fluoropyrimidine + irinotecan; IV, intravenous; 5-FU, fluorouracil.

\section{Efficacy and safety evaluation}

The objective of the study was to evaluate the overall response rate (ORR), disease-control rate (DCR), overall survival (OS), PFS, and toxicity of bevacizumab in patients with $\mathrm{mCRC}$ treated by bevacizumab plus chemotherapy. OS was defined as the duration from the initiation of the therapy to the date of death of any cause or at the end of this experiment. PFS was defined as the duration from the initiation of the therapy to the confirmation date of progressive disease, or death of any cause.

All of the patients were included in the PFS and OS analyses if they had been treated with bevacizumab at least three times. Individual patients who had severe adverse effects but without clinical or radiographic evidence of progressive disease were taken off therapy. Patients without complete clinical data were excluded.

Tumor responses were evaluated according to the Response Evaluation Criteria in Solid Tumors guidelines. ${ }^{12}$ Progression was defined as a $20 \%$ increase in the sum of diameters of the target lesions. Toxicities were graded using the National Cancer Institute Common Terminology Criteria for Adverse Events (version 3.1). ${ }^{13}$

Lesions of individual patients were assessed at baseline (within 4 weeks before starting chemotherapy) and every 6-8 weeks after treatment by radiology, which consisted of a bone scan, ultrasound of lymph nodes, chest computed tomography scan, and abdominopelvic computed tomography scan. 


\section{Statistical analysis}

Data are expressed as real case number and percentage and were analyzed using SPSS 17.0 (IBM, Armonk, NY, USA). Survival curves were estimated using the Kaplan-Meier method and analyzed by log-rank test. A $P$-value of $<0.05$ was considered statistically significant.

\section{Results}

A total of 96 patients with mCRC received more than three cycles of bevacizumab-plus-chemotherapy treatment. The median age of the patients in the study was 53.6 years, with 72 males and 24 females. Combined chemotherapy regimens included oxaliplatin-containing chemotherapy $(50.0 \%)$, irinotecan-containing chemotherapy $(40.6 \%)$, and other chemotherapy (9.4\%). Primary tumors of 60 patients $(62.5 \%)$ were located in the colon, the rest $(36,37.5 \%)$ in the rectum. The most common metastatic sites were liver and/or lung (38.6\%). Thirty-nine (40.6\%) patients had received adjuvant chemotherapy after operation. Thirty-six (37.5\%) patients were treated with bevacizumab combined chemotherapy as a first-line treatment, $41(42.7 \%)$ as a second-line treatment, and $19(19.8 \%)$ as a third-line (or later) treatment. A median of five (range 3-19) cycles of bevacizumab were administered. Major patient demographics are summarized in Table 2.

\section{Efficacy}

At the final cutoff date (August 20, 2012), 54 patients exhibited progression (56.3\%) and 39 (40.6\%) patients died. Twenty-seven patients $(28.1 \%)$ achieved partial response and 48 patients $(50.0 \%)$ achieved stable disease (SD), exhibiting an ORR of $28.1 \%$ (complete response and partial response) and a DCR (complete response and stable disease) of $78.1 \%$. The response rates of for the first-line, secondline, and third-line (or later) treatments were $41.7 \%, 21.9 \%$, and $15.8 \%$, respectively (Table 3 ). The median follow-up for all the patients is 14.70 months. The median durations of the PFS and OS were 8.13 months and 14.80 months, respectively (Table 4 and Figure 1). The median PFSs for the first-line, second-line, and third-line (or later) treatments were $12.70,8.30$, and 6.40 months, respectively. The median OSs for the first-line, second-line, and third-line (or later) treatments were 24.03 months, 14.90 months, and 11.03 months, respectively (Table 4).

\section{Toxicity}

There was no toxic death. Severe adverse events, such as bowel perforation, thromboembolism event, severe
Table 2 Baseline demographic characteristics

\begin{tabular}{|c|c|}
\hline Characteristics & n (\%) \\
\hline$n$ & 96 \\
\hline Age, median (range) & $53.6(32-75)$ \\
\hline \multicolumn{2}{|l|}{ Sex } \\
\hline Male & $72(75.0)$ \\
\hline Female & $24(25.0)$ \\
\hline \multicolumn{2}{|l|}{ Primary tumor site } \\
\hline Colon & $60(62.5)$ \\
\hline Rectal & $36(37.5)$ \\
\hline \multicolumn{2}{|l|}{ ECOG performance } \\
\hline $0-1$ & $86(89.6)$ \\
\hline 2 & $10(10.4)$ \\
\hline \multicolumn{2}{|l|}{ Metastatic sites } \\
\hline Liver only & $23(24.0)$ \\
\hline Lung only & $14(14.6)$ \\
\hline One site except liver and lung & $8(8.3)$ \\
\hline More than I site & $5 I(53.1)$ \\
\hline \multicolumn{2}{|l|}{ Number of metastatic sites } \\
\hline I & $45(46.9)$ \\
\hline$>1$ & $5 I(53.1)$ \\
\hline \multicolumn{2}{|l|}{ Histologic type } \\
\hline Well & $4(4.2)$ \\
\hline Moderate & $76(79.2)$ \\
\hline Poor & $4(4.2)$ \\
\hline Unknown & $5(5.2)$ \\
\hline Mucinous adenocarcinoma & $7(7.2)$ \\
\hline \multicolumn{2}{|l|}{ Adjuvant chemotherapy } \\
\hline Yes & $39(40.6)$ \\
\hline FOLFOX & $14(35.9)$ \\
\hline XELOX & $14(35.9)$ \\
\hline FOLFIRI & $2(5.1)$ \\
\hline CAP & $5(12.8)$ \\
\hline Others & $4(10.3)$ \\
\hline No & $57(59.4)$ \\
\hline \multicolumn{2}{|l|}{ Line number of bevacizumab } \\
\hline Ist line & $36(37.5)$ \\
\hline 2nd line & $4 I(42.7)$ \\
\hline $3 r d$ or later line & $19(19.8)$ \\
\hline \multicolumn{2}{|l|}{ Chemotherapy combined with bevacizumab } \\
\hline Oxaliplatin-containing chemotherapy & $48(50.0)$ \\
\hline Irinotecan-containing chemotherapy & $39(40.6)$ \\
\hline Others & $9(9.4)$ \\
\hline
\end{tabular}

Abbreviations: ECOG, Eastern Cooperative Oncology Group; FOLFOX, fluoropyrimidine + oxaliplatin; XELOX, oxaliplatin + capecitabine; FOLFIRI, fluoropyrimidine + irinotecan; CAP, capecitabine.

bleeding, or reversible posterior leukoencephalopathy syndrome, were not observed. Since we tended to withdraw the drug immediately after hypertension or hemorrhage occurred to ensure safety, three patients stopped using the drug because of the adverse events. Overall, the addition of bevacizumab to chemotherapy was well tolerated. Main adverse effects included hypertension, hemorrhage, hematochezia, poor wound healing, and thrombotic events. A total of 99 patients who received at least one dose of bevacizumab accepted safety assessment. It is worth mentioning 
Table 3 Response to treatment

\begin{tabular}{llllll}
\hline Response & Patients & CR (\%) & PR (\%) & SD (\%) & PD (\%) \\
\hline Overall & 96 & $0(0)$ & $27(28.1)$ & $48(50.0)$ & $21(21.9)$ \\
Ist line & 36 & $0(0)$ & $15(41.7)$ & $17(47.2)$ & $4(11.1)$ \\
2nd line & 41 & $0(0)$ & $9(21.9)$ & $22(53.7)$ & $10(24.4)$ \\
3rd line & 19 & $0(0)$ & $3(15.8)$ & $9(47.4)$ & $7(36.8)$ \\
\hline
\end{tabular}

Abbreviations: $C R$, complete response; PR, partial response; SD, stable disease; $\mathrm{PD}$, progressive disease.

that one patient stopped using because of uncontrolled hypertension and proteinuria, but after a 3-months interval he started again and the adverse effect became tolerable. Details of the incidence of selected adverse events are presented in Table 5.

\section{Discussion}

Bevacizumab is a standard therapy approved for first- and second-line treatment in patients with $\mathrm{mCRC}$ by the FDA. Multiple clinical trials have proven the use of bevacizumab results in an improvement in PFS and OS. Approval for firstline mCRC treatment was mainly based on the supportive results of two studies: a randomized, double-blind, placebocontrolled phase III trial with 813 patients that evaluated the effect of additional bevacizumab combined with irinotecan, bolus fluorouracil, and leucovorin (IFL), ${ }^{7}$ and a phase II, randomized, placebo-controlled trial that evaluated the effect of additional bevacizumab combined with fluorouracil and leucovorin, ${ }^{8}$ both of which demonstrated the addition of bevacizumab to chemotherapy significantly improved PFS and OS. ${ }^{7,8}$

Based on these data, more clinical trials were conducted. The NO16966 study reported that PFS and OS increased in patients with $\mathrm{mCRC}$ treated with bevacizumab combined with XELOX or FOLFOX, which resulted in mPFS of 9.3 versus 7.4 months and mOS of 21.6 versus 19.0 months in the XELOX group, and PFS of 9.4 versus 8.6 months and

Table 4 Analysis of survival

\begin{tabular}{llll}
\hline $\begin{array}{l}\text { End } \\
\text { point }\end{array}$ & $\begin{array}{l}\text { Median follow-up } \\
\text { duration* }(\text { range })\end{array}$ & $\begin{array}{l}\text { mPFS } \\
(95 \% \mathrm{Cl}, \text { month) }\end{array}$ & $\begin{array}{l}\text { mOS } \\
(95 \% \mathrm{CI}, \text { month })\end{array}$ \\
\hline Overall & $34.47(6.70-81.70)$ & $8.13(6.31-10.35)$ & $\begin{array}{l}14.80 \\
(7.87-21.73)\end{array}$ \\
Ist line & $36.07(6.70-62.73)$ & $12.70(7.76-17.63)$ & $\begin{array}{l}24.03 \\
(7.08-40.98)\end{array}$ \\
& & & 14.90 \\
2nd line & $40.97(7.90-81.70)$ & $8.30(6.66-10.01)$ & $\begin{array}{l}8.37-21.42) \\
11.03\end{array}$ \\
3rd or & $32.47(14.07-40.70)$ & $6.40(5.46-7.33)$ & $(8.17-21.13)$ \\
later line & & &
\end{tabular}

Note: *From diagnosis to last follow-up date or death date.

Abbreviations: mOS, median overall survival; mPFS, median progression-free survival.


Figure I (A) Curve for progression-free survival in patients with metastatic colorectal cancer treated with bevacizumab combined chemotherapy; (B) curve for overall survival in patients with metastatic colorectal cancer treated with bevacizumab combined chemotherapy.

mOS of 21.0 versus 18.9 months in the FOLFOX group. ${ }^{14}$ Another phase III trial (CAIRO2) also demonstrated mPFS of 10.7 months and mOS of 20.3 months in the XELOXplus-bevacizumab arm. ${ }^{15}$ Although large numbers of subjects have been enrolled in clinical trials and positive results

Table 5 Selected adverse effects (total number $=99$ )

\begin{tabular}{|c|c|c|}
\hline Adverse event & $\begin{array}{l}\text { Grade I-2, } \\
\text { n (\%) }\end{array}$ & $\begin{array}{l}\text { Grade 3-4, } \\
\text { n (\%) }\end{array}$ \\
\hline \multicolumn{3}{|l|}{ Chemotherapy-related } \\
\hline Neotropenia & $4 I(4 I .4)$ & $28(28.3)$ \\
\hline Thrombocytopenia & $24(24.2)$ & $12(12.1)$ \\
\hline Neurosensory toxicity & $28(28.3)$ & $8(8.0)$ \\
\hline Vomiting & $59(59.6)$ & $32(32.3)$ \\
\hline Diarrhea & $18(18.2)$ & $6(6.0)$ \\
\hline Jaundice or elevated bilirubin & $2(2.0)$ & $0(0)$ \\
\hline Hepatic dysfunction & $2(2.0)$ & $0(0)$ \\
\hline \multicolumn{3}{|l|}{ Bevacizumab-related } \\
\hline Nosebleed & $12(12.1)$ & $2(2.0)$ \\
\hline Hypertension & $12(12.1)$ & $5(5.1)$ \\
\hline Hemorrhage & $7(7.1)$ & $\mathrm{I}(\mathrm{I} .0)$ \\
\hline Proteinuria & $3(3.0)$ & $3(3.0)$ \\
\hline Thrombosis & $8(8.0)$ & $0(0)$ \\
\hline Gastrointestinal perforation & $0(0)$ & $0(0)$ \\
\hline Poor wound healing & $2(2.0)$ & $0(0)$ \\
\hline Reversible posterior & $0(0)$ & $0(0)$ \\
\hline leukoencephalopathy syndrome & & \\
\hline
\end{tabular}


Table 6 Summary of the clinical trials investigating the efficacy of bevacizumab combined with chemotherapy in patients with mCRC

\begin{tabular}{|c|c|c|c|c|c|c|c|c|}
\hline Study & Area & $\mathbf{n}$ & Phase & $\begin{array}{l}\text { Treatment } \\
\text { line }\end{array}$ & Experimental arm & ORR & $\begin{array}{l}\text { mPFS } \\
\text { (months) }\end{array}$ & $\begin{array}{l}\text { mOS } \\
\text { (months) }\end{array}$ \\
\hline \multirow[t]{2}{*}{ Hurwitz et $\mathrm{al}^{7}$} & US & 402 & III & Ist & IFL/placebo & 34.8 & 6.2 & 15.6 \\
\hline & & 411 & & & IFL/BV & 44.8 & 10.6 & 20.3 \\
\hline \multirow[t]{2}{*}{ Kabbinavar et a $\left.\right|^{8}$} & US & 105 & II & Ist & FU/LV/placebo & 15.2 & 5.5 & 12.9 \\
\hline & & 104 & & & FU/LV/BV & 26.0 & 9.2 & 16.6 \\
\hline \multirow[t]{2}{*}{ Cassidy et $\mathrm{al}^{1 / 4}$} & US & $546 / 274$ & III & Ist & XELOX/XELOX + BV & NA & $7.4 / 9.3$ & $19.0 / 21.6$ \\
\hline & & $573 / 274$ & & & FOLFOX/FOLFOX + BV & & $8.6 / 9.4$ & $|8.9 / 2| .0$ \\
\hline \multirow[t]{3}{*}{ Giantonio et al ${ }^{10}$} & US & 286 & III & 2nd & FOLFOX/FOLFOX + BV & 22.7 & 7.3 & 12.9 \\
\hline & & 291 & & & FOLFOX4 & 8.6 & 4.7 & 10.8 \\
\hline & & 243 & & & Bevacizumab & 3.3 & 2.7 & 10.2 \\
\hline Park et $\mathrm{al}^{22}$ & $\mathrm{KR}$ & 40 & Retro & 2 nd or later & BV + FOLFIRI/FOLFOX & 7.5 & 6.13 & 14.0 \\
\hline Toshihiko Doi ${ }^{16}$ & $J P$ & 57 & $\mathrm{I} / \mathrm{II}$ & Ist & BV + XELOX & 72 & 11.0 & 27.4 \\
\hline \multirow[t]{2}{*}{ Guan et $\mathrm{al}^{17}$} & $\mathrm{CN}$ & 214 & III & Ist & $\mathrm{mlFL}$ & 17 & 4.2 & 13.4 \\
\hline & & & & & $\mathrm{mIFL/BV}$ & 35 & 8.3 & 18.7 \\
\hline Lièvre et $\mathrm{a}^{23}$ & $\mathrm{FR}$ & 31 & Retro & 2nd or later & BV + FOLFIRI/FOLFOX & 32.2 & 9.7 & 18.4 \\
\hline
\end{tabular}

Abbreviations: US, United States; KR, Korea; CN, China; JP, Japan; FR, France; IFL, irinotecan + fluoropyrimidine+leucovorin; BV, bevacizumab; FU, fluoropyrimidine; Retro, retrospective; FOLFOX, fluoropyrimidine + oxaliplatin; FOLFIRI, fluoropyrimidine + irinotecan; XELOX, oxaliplatin + capecitabine; NA, not applicable; mOS, median overall survival; mPFS, median progression-free survival; ORR, overall response rate.

have been proved, most of the clinical trials have been performed in Western countries. Clinical trials performed in the Asian region have mostly contained small samples. ${ }^{16}$ A prospective, multicenter, randomized, open-label, phase III trial conducted in the People's Republic of China with 214 patients enrolled compared the efficacy of mIFL plus bevacizumab with mIFL alone as a first-line regimen. The results demonstrated a significant improvement in ORR (35\% vs $17 \%)$, mPFS (8.3 vs 4.2 months), and mOS (18.7 vs 13.4 months).${ }^{17} \mathrm{~A}$ summary of the clinical trials investigating the efficacy of bevacizumab combined with chemotherapy in patients with mCRC is shown in Table 6.

In this present retrospective study, ORR was $28.1 \%$ for all of the patients, and mPFS and mOS were 8.13 and 14.80 months, respectively. The response rates for first-line, second-line and third-line (or later) treatments were $41.7 \%$, $21.9 \%$, and $15.8 \%$, respectively.

Fifty-five of the 96 patients accepted KRAS status exam, this resulted to 28 KRAS mutations and 27 KRAS wildtype; KRAS status of the other 41 patients was unknown. Unlike cetuximab, the use of which is restricted to patients with KRAS wild-type tumors because patients with a tumor harboring a KRAS mutation are resistant to anti-epidermal growth-factor receptor therapy, the efficacy of bevacizumab is not influenced by KRAS status. ${ }^{18,19}$ In this study, we compared efficacy between different KRAS statuses and found no significant difference among them, which proved the status of KRAS had no prognostic value in patients using bevacizumab.

There were 21 patients also using cetuximab at some point in the continuum of care. Research has been conducted and proved that combination therapy with more than one biologic agent is not associated with improved outcomes and can cause increased toxicity. The PACCE trial demonstrated that regardless of KRAS status, the combination of bevacizumab and panitumumab with chemotherapy significantly resulted in significantly shorter PFS and inferior quality of life. ${ }^{20}$ In the CAIRO2 trial, the addition of cetuximab to capecitabine, oxaliplatin, and bevacizumab showed a similar result. ${ }^{15} \mathrm{~A}$ retrospective analysis provided support for a sequential use of bevacizumab, cetuximab, and three cytotoxic drugs - fluoropyrimidines, irinotecan, and oxaliplatin - was associated with increased survival, which was not found to be associated with the order in which these drugs were received. ${ }^{21}$ In the present study, we compared the survival difference between patients taking both bevacizumab and cetuximab and patients taking only bevacizumab with the log-rank test. Although there was a difference in survival between these two groups, the benefit was not significant ( 10.30 vs 5.87 months, $P=1.03$ ). That may have been because of the small sample size.

\section{Conclusion}

The efficacy and safety of bevacizumab plus chemotherapy in this study was basically consistent with that reported in Western patients. It could be concluded from this retrospective study that bevacizumab plus chemotherapy was effective for Chinese patients with $\mathrm{mCRC}$, and the adverse events were tolerant and manageable.

\section{Acknowledgment}

This study was sponsored by Wu Jieping Medical Foundation, no 32065711201. 


\section{Disclosure}

The authors report no conflicts of interest in this work.

\section{References}

1. Globocan 2008. Estimated cancer incidence, mortality, prevalence and disability-adjusted life years (DALYs) worldwide in 2008. Available from: http://globocan.iarc.fr. Accessed January 13, 2013.

2. Kim GP, Sargent DJ, Mahoney MR, et al. Phase III noninferiority trial comparing irinotecan with oxaliplatin, fluorouracil, and leucovorin in patients with advanced colorectal carcinoma previously treated with fluorouracil: N9841. J Clin Oncol. 2009;27:2848-2854.

3. Koopman M, Antonini NF, Douma J, et al. Sequential versus combination chemotherapy with capecitabine, irinotecan, and oxaliplatin in advanced colorectal cancer (CAIRO): a phase III randomised controlled trial. Lancet. 2007;370:135-142.

4. Tol J, Koopman M, Cats A, Rodenburg CJ, et al. Chemotherapy, bevacizumab, and cetuximab in metastatic colorectal cancer. $N$ Engl J Med. 2009;360:563-572.

5. Wang TF, Lockhart AC. Aflibercept in the treatment of metastatic colorectal cancer. Clin Med Insights Oncol. 2012;6:19-30.

6. Takahashi S. Vascular endothelial growth factor (VEGF), VEGF receptors and their inhibitors for antiangiogenic tumor therapy. Biol Pharm Bull. 2011;34:1785-1788.

7. Hurwitz H, Fehrenbacher L, Novotny W, et al. Bevacizumab plus irinotecan, fluorouracil, and leucovorin for metastatic colorectal cancer. N Engl J Med. 2004;350:2335-2342.

8. Kabbinavar FF, Hambleton J, Mass RD, Hurwitz HI, Bergsland E, Sarkar S. Combined analysis of efficacy: the addition of bevacizumab to fluorouracil/leucovorin improves survival for patients with metastatic colorectal cancer. J Clin Oncol. 2005;23:3706-3712.

9. Saltz LB, Clarke S, Díaz-Rubio E, et al. Bevacizumab in combination with oxaliplatin-based chemotherapy as first-line therapy in metastatic colorectal cancer: a randomized phase III study. J Clin Oncol. 2008;26:2013-2019.

10. Giantonio BJ, Catalano PJ, Meropol NJ, et al. Bevacizumab in combination with oxaliplatin, fluorouracil, and leucovorin (FOLFOX4) for previously treated metastatic colorectal cancer: results from the Eastern Cooperative Oncology Group Study E3200. J Clin Oncol. 2007;25:1539-1544.

11. Cohen MH, Gootenberg J, Keegan P, Pazdur R. FDA drug approval summary: bevacizumab plus FOLFOX4 as second-line treatment of colorectal cancer. Oncologist. 2007;12:356-361.
12. Eisenhauer EA, Therasse P, Bogaerts J, et al. New response evaluation criteria in solid tumours: revised RECIST guideline (version 1.1). Eur J Cancer. 2009;45:228-247.

13. Cancer Therapy Evaluation Program. Common terminology criteria for adverse events v 3.0 (CTCAE). 2006. Available from: http:// www.eortc.be/services/doc/ctc/ctcaev3.pdf. Accessed February 28, 2013.

14. Cassidy J, Clarke S, Díaz-Rubio E, et al. XELOX vs FOLFOX-4 as first-line therapy for metastatic colorectal cancer: NO16966 updated results. Br J Cancer. 2011;105:58-64.

15. Tol J, Koopman M, Rodenburg CJ, et al. A randomised phase III study on capecitabine, oxaliplatin and bevacizumab with or without cetuximab in first-line advanced colorectal cancer, the CAIRO2 study of the Dutch Colorectal Cancer Group (DCCG). An interim analysis of toxicity. Ann Oncol. 2008;19:734-738.

16. Toshihiko Doi, Narikazu Boku, Ken Kato et al. Phase I/II study of Capecitabine plus Oxaliplatin (XELOX) plus Bevacizumab as firstline therapy in Japanese patients with metastatic colorectal cancer. Jpn J Clin Oncol. 2010;40(10):913-920.

17. Guan ZZ, Xu JM, Luo RC, et al. Efficacy and safety of bevacizumab plus chemotherapy in Chinese patients with metastatic colorectal cancer: a randomized phase III ARTIST trial. Chin J Cancer. 2011; 30:682-689.

18. Karapetis CS, Khambata-Ford S, Jonker DJ, et al. K-ras mutations and benefit from cetuximab in advanced colorectal cancer. $N$ Engl $J$ Med. 2008;359:1757-1765.

19. Lièvre A, Bachet JB, Boige V, et al. KRAS mutations as an independent prognostic factor in patients with advanced colorectal cancer treated with cetuximab. J Clin Oncol. 2008;26:374-379.

20. Hecht JR, Mitchell E, Chidiac T, et al. A randomized phase IIIB trial of chemotherapy, bevacizumab, and panitumumab compared with chemotherapy and bevacizumab alone for metastatic colorectal cancer. J Clin Oncol. 2009;27:672-280.

21. Grothey A, Sargent D, Goldberg RM, Schmoll HJ. Survival of patients with advanced colorectal cancer improves with the availability of fluorouracil-leucovorin, irinotecan, and oxaliplatin in the course of treatment. J Clin Oncol. 2004;22:1209-1214.

22. Park LC, Lee HS, Shin SH, et al. Bevacizumab as a second- or later-line of treatment for metastatic colorectal cancer. World $J$ Gastroenterol. 2012;18:1104-1109.

23. Lièvre A, Samalin E, Mitry E, et al. Bevacizumab plus FOLFIRI or FOLFOX in chemotherapy-refractory patients with metastatic colorectal cancer: a retrospective study. BMC Cancer. 2009; 9:347.
OncoTargets and Therapy

\section{Publish your work in this journal}

OncoTargets and Therapy is an international, peer-reviewed, open access journal focusing on the pathological basis of all cancers, potential targets for therapy and treatment protocols employed to improve the management of cancer patients. The journal also focuses on the impact of management programs and new therapeutic agents and protocols on

\section{Dovepress}

patient perspectives such as quality of life, adherence and satisfaction. The manuscript management system is completely online and includes a very quick and fair peer-review system, which is all easy to use. Visit http://www.dovepress.com/testimonials.php to read real quotes from published authors. 